\title{
Correction to: Generalized interval-valued picture fuzzy linguistic induced hybrid operator and TOPSIS method for linguistic group decision-making
}

\author{
${\text { Muhammad } \text { Qiyas }^{1} \text { (1) } \cdot \text { Saleem Abdullah }}^{1} \cdot$ Yasser D. Al-Otaibi $^{2} \cdot$ Muhammad Aslam $^{3}$
}

Published online: 17 March 2021

(C) Springer-Verlag GmbH Germany, part of Springer Nature 2021

\section{Correction to: Soft Computing}

https://doi.org/10.1007/s00500-020-05508-0

The originally published article the affiliation of the article Muhammad Aslam was incorrect. The correction affiliation has been provided below

Department of Mathematics, College of Science, King Khalid University, Abha, Saudi Arabia

The original article has been corrected.

Publisher's Note Springer Nature remains neutral with regard to jurisdictional claims in published maps and institutional affiliations.

The original article can be found online at https:// doi.org/10.1007/s00500-020-05508-0.

Saleem Abdullah

saleemabdullah@awkum.edu.pk

Muhammad Qiyas

muhammadqiyas@awkum.edu.pk

Yasser D. Al-Otaibi

yalotaibi@kau.edu.sa

Muhammad Aslam

draslamqau@yahoo.com

1 Department of Mathematics, Abdul Wali Khan University Mardan, Mardan, Pakistan

2 Department of Information Systems, Faculty of Computing and Information Technology in Rabigh, King Abdulaziz University, Jeddah 21589, Saudi Arabia

3 Department of Mathematics, College of Science, King Khalid University, Abha, Saudi Arabia 